\title{
EXPOSURE TO PSYCHOACTIVE COMPOUNDS AMONGST STUDENTS OF MEDICAL UNIVERSITY
}

\author{
Krystyna Kowalczuk, Elżbieta Krajewska-Kułak \\ Department of Integrated Medical Care, Medical University of Bialystok, Bialystok, Poland
}

\section{SUMMARY}

Objective: The aim of this study was to assess the frequency of exposure to psychoactive compounds amongst students of the Medical University of Bialystok.

Method: This cross-sectional study included 504 students selected by means of stratified sampling based on the university faculty, study discipline and year, and participant's gender.

Results: Nearly three fourths of our respondents have contact with their student colleagues who use psychoactive compounds, or have heard that such individuals exist. Approximately one fourth of the students declared that they considered using psychoactive compounds at least once. Marijuana and hashish were the psychoactive compounds our respondents used most frequently. Median age of the first contact with these substances was 18 years. Alarmingly high fraction of respondents declared that most of psychoactive compounds included in the study is easily available and obtaining them would not take them longer than one day. Furthermore, $15 \%$ of respondents admitted to being involved in the distribution of psychoactive compounds.

Conclusion: The exposure of medical university students to psychoactive compounds represents similar problem as in their peers studying other disciplines. However, in view of its specific consequences (including potential threat to patients' health and life), the problem should not be underestimated.

Key words: hashish, illicit drugs, marijuana, substance abuse

Address for correspondence: K. Kowalczuk, Department of Integrated Medical Care, Medical University of Bialystok, ul. M. Skłodowskiej-Curie 7A, 15-096 Bialystok, Poland. E-mail: krystyna.kowalczuk@umb.edu.pl

https://doi.org/10.21101/cejph.a4626

\section{INTRODUCTION}

Similarly to other post-communist countries, in Poland the problem of psychoactive substance use has been a sort of social taboo for decades. However, the socioeconomic changes that occurred at the end of the previous century are reflected by the growing importance of substance dependence problems, which may be the result of easier access to various psychoactive compounds (1).

The results of recent studies suggest an increase in use of psychoactive substance by Polish adolescents. Furthermore, this type of behaviour is not only associated with physical dependence and respective syndrome, but also has many health and social consequences (2). Equally important are the consequences of recreational use of so-called soft drugs (e.g. marijuana smoking) - road accidents, acts of violence, unwanted sexual contacts, and others (3-6).

Students represent one of the main risk groups of recreational use of psychoactive compounds (7-9). Thus, many studies of this age group exposure to various narcotic substances have been undertaken in recent years (10-16). Due to their future job and characteristics of academic classes, contact with psychoactive substances constitutes a specific threat in case of medical university students (17-20). However, the extent of the problems associated with using such substances by this group of adolescents has not been examined in detail $(18,21,22)$. Therefore, the aim of this cross-sectional study was to assess the frequency of exposure to psychoactive compounds amongst students of the Medical University of Bialystok.

\section{MATERIALS AND METHODS}

The study performed in March 2011 included 504 students from the Medical University of Bialystok. This sample, corresponding to $10 \%$ of the entire student population, was selected by means of stratified sampling based on the university faculty, study discipline and year, and participant's gender. Characteristics of study participants are presented in Table 1.

The protocol of this study was approved by the Local Bioethical Committee of the Medical University of Bialystok. All participants were familiarized with the study objectives and protocol, and gave their written consent to participate.

All participants completed a standardized anonymous questionnaire dealing with their contacts and opinions on psychoactive compounds. The questionnaire was prepared and provided by the PBS DGA Research Agency (Sopot, Poland). The random diagnostic survey mode was used. Statistical analysis of the results was carried out using Statistica 10 (StatSoft, Tulsa OK, USA) package. Statistical characteristics of discrete variables 
Table 1. Socio-demographic characteristics of study participants $(N=504)$

\begin{tabular}{|c|c|c|}
\hline Variable & Mean \pm SD & Range \\
\hline Age (years) & $21.7 \pm 2.3$ & $18-27$ \\
\hline Variable & $n$ & $\%$ \\
\hline \multicolumn{3}{|l|}{ Gender } \\
\hline Males & 112 & 22.2 \\
\hline Females & 392 & 77.8 \\
\hline \multicolumn{3}{|l|}{ Study discipline } \\
\hline Medicine/dentistry & 192 & 38.1 \\
\hline Pharmacy & 127 & 25.2 \\
\hline Health sciences & 185 & 36.7 \\
\hline \multicolumn{3}{|l|}{ Year of study } \\
\hline 1 & 126 & 25.0 \\
\hline$\|$ & 108 & 21.4 \\
\hline III & 78 & 15.5 \\
\hline IV & 73 & 14.5 \\
\hline V & 80 & 15.9 \\
\hline VI & 39 & 7.7 \\
\hline \multicolumn{3}{|l|}{ Place of residence } \\
\hline Village & 78 & 15.5 \\
\hline Town up to 5,000 inhabitants & 40 & 7.9 \\
\hline Town between 5,000 and 50,000 & 112 & 22.2 \\
\hline Town between 50,000 and 200,000 & 99 & 19.6 \\
\hline City above 200,000 & 175 & 34.7 \\
\hline
\end{tabular}

were presented as frequency distributions. Depending on the results, the characteristics of these variables were presented as arithmetic means and standard deviations (SD) or medians and interquartile ranges (q25-q75).

\section{RESULTS}

Nearly $38 \%$ of respondents admitted that the issue of psychoactive compound use constitutes a serious problem amongst students. However, slightly larger percentage of respondents (42\%) did not admit this as a serious problem and $20 \%$ of them did not give clear answer to this question. More than half of respondents were in contact with their student colleagues who use psychoactive compounds and $21 \%$ of them have heard that such individuals exist. More than half of respondents declared that these individuals use psychoactive compounds during their preparation for tests or exams. Approximately one fourth of investigated students declared that they have considered using psychoactive compounds at least once.

Marijuana and hashish were the psychoactive compounds our respondents used most frequently. However, most of the participants did not use them more frequently than several times. Other psychoactive substances included in this study were used marginally. Median age of the first contact with marijuana and hashish was 18 years (Table 2).

The majority of our respondents $(79.7 \%)$, who declared previous experiences with psychoactive compounds, stated that marijuana and hashish were the first substances of this kind they ever used. During the 12 months prior to this study, almost $12 \%$ of our respondents used marijuana and hashish occasionally; the other compounds were used marginally. Besides a few episodes of using other substances, marijuana and hashish were the only psychoactive compounds our participants declared to use during 30 days prior to the study.

In the vast majority of cases (84.4\%), the respondents obtained their first psychoactive compounds from their friends. The respondents who declared using psychoactive compounds during the 12 months prior to the study also received them from friends $(69 \%)$, but $22 \%$ received them against payments. This trend shows that number of respondents became addicted to marijuana

Table 2. Answer distribution to the question "Have you ever used any of these compounds; if so how old were you and how many times did you use this compound throughout your life?" $(N=504)$

\begin{tabular}{|l|c|c|c|c|c|c|c|c|}
\hline Type of substance & Age & Never & $1-2$ times & $3-5$ times & $6-9$ times & $10-19$ times & 20-39 times & $\geq 40$ times \\
\hline $\begin{array}{l}\text { Glues, solvents and other } \\
\text { inhalation agents }\end{array}$ & $17(10.5-19)$ & $495(98.2 \%)$ & $5(1.0 \%)$ & $3(0.6 \%)$ & 0 & 0 & 0 & $1(0.2 \%)$ \\
\hline Marijuana or hashish & $18(16-20)$ & $372(73.8 \%)$ & $61(12.1 \%)$ & $40(7.9 \%)$ & $12(2.4 \%)$ & $6(1.2 \%)$ & $3(0.6 \%)$ & $10(2.0 \%)$ \\
\hline Amphetamine (speed) & $18(17-21)$ & $480(95.2 \%)$ & $14(2.8 \%)$ & $2(0.4 \%)$ & $3(0.6 \%)$ & $2(0.4 \%)$ & $2(0.4 \%)$ & $1(0.2 \%)$ \\
\hline Ecstasy & $18(17-19.5)$ & $480(95.2 \%)$ & $16(3.2 \%)$ & $4(0.8 \%)$ & $2(0.4 \%)$ & 0 & 0 & $2(0.4 \%)$ \\
\hline LSD & $20(18-21)$ & $493(97.8 \%)$ & $7(1.4 \%)$ & $1(0.2 \%)$ & $3(0.6 \%)$ & 0 & 0 & 0 \\
\hline Psychoactive mushrooms & $20(19-20)$ & $495(98.2 \%)$ & $6(1.2 \%)$ & $1(0.2 \%)$ & 0 & $1(0.2 \%)$ & 0 & $1(0.2 \%)$ \\
\hline Crack & $17(17-19)$ & $498(98.8 \%)$ & $4(0.8 \%)$ & $1(0.2 \%)$ & 0 & $1(0.2 \%)$ & 0 & 0 \\
\hline Heroin (including "brown sugar") & $17(14-20)$ & $500(99.2 \%)$ & $1(0.2 \%)$ & $1(0.2 \%)$ & $1(0.2 \%)$ & $1(0.2 \%)$ & 0 & 0 \\
\hline So-called Polish heroin & $20(16.5-22)$ & $497(98.6 \%)$ & $3(0.6 \%)$ & $2(0.4 \%)$ & 0 & $1(0.2 \%)$ & 0 & $1(0.2 \%)$ \\
\hline Cocaine & $20(20-23)$ & $495(98.2 \%)$ & $4(0.8 \%)$ & $2(0.4 \%)$ & $2(0.4 \%)$ & $1(0.2 \%)$ & 0 & 0 \\
\hline Anabolic steroids & $18(18-20)$ & $495(98.2 \%)$ & $2(0.4 \%)$ & $2(0.4 \%)$ & $1(0.2 \%)$ & $1(0.2 \%)$ & $1(0.2 \%)$ & $2(0.4 \%)$ \\
\hline $\begin{array}{l}\text { Prescription hypnotics and } \\
\text { psychotropic medications }\end{array}$ & $20(18-21)$ & $486(96.4 \%)$ & $7(1.4 \%)$ & $6(1.2 \%)$ & $3(0.6 \%)$ & 0 & $1(0.2 \%)$ & $1(0.2 \%)$ \\
\hline Other compounds & $21(21-21)$ & $502(99.6 \%)$ & $1(0.2 \%)$ & $1(0.2 \%)$ & 0 & 0 & 0 & 0 \\
\hline
\end{tabular}

Age of the first use presented as median and interquartile range (in parenthesis). 
Table 3. Answer distribution to the question "Where have you usually obtained psychoactive compounds during recent 12 months?"

\begin{tabular}{|l|c|}
\hline Answer & $\mathbf{n ~ ( \% )}$ \\
\hline Pharmacy, shop & $2(3.1)$ \\
\hline Street, park, railway/underground station & $7(10.8)$ \\
\hline Staircase & $1(1.5)$ \\
\hline University & $5(7.7)$ \\
\hline Student house & $9(13.8)$ \\
\hline Place of work & 0 \\
\hline Pub/disco/student club & $3(4.6)$ \\
\hline At a party & $28(43.1)$ \\
\hline From a dealer & $5(7.7)$ \\
\hline Other places & $5(7.7)$ \\
\hline Total & $65(100.0)$ \\
\hline
\end{tabular}

Table 4. Answer distribution to the question "Why do you usually use psychoactive compounds? Please, refer to all situations during recent 12 months."

\begin{tabular}{|l|c|}
\hline Reason & $\mathbf{n}(\%)$ \\
\hline Pleasure & $58(11.5)$ \\
\hline Relax & $60(11.9)$ \\
\hline To experience something extraordinary & $29(5.8)$ \\
\hline Not no differ from a group & $8(1.6)$ \\
\hline To distract others' attention & $9(1.8)$ \\
\hline To encourage myself to contact with other people & $9(1.8)$ \\
\hline To learn something quickly & $12(2.4)$ \\
\hline To gain more energy for playing & $20(4.0)$ \\
\hline To forget my problems & $18(3.6)$ \\
\hline Not to sleep & $12(2.4)$ \\
\hline To eat less & $6(1.2)$ \\
\hline I have nothing else to do/not to get bored & $11(2.2)$ \\
\hline Other reasons & $10(2.0)$ \\
\hline I do not remember a reason & $7(1.4)$ \\
\hline
\end{tabular}

Table 5. Answer distribution to the question "Considering recent 12 months, have you usually smoked marijuana or hashish alone or in company of others?"

\begin{tabular}{|l|c|}
\hline Answer & $\mathbf{n}(\%)$ \\
\hline Usually alone & $2(3.2)$ \\
\hline Alone or in company & $9(14.5)$ \\
\hline Usually in company & $48(77.4)$ \\
\hline Hard to say & $3(4.8)$ \\
\hline Total & $62(100.0)$ \\
\hline
\end{tabular}

and hashish. Psychoactive compounds were mostly obtained at parties (43\%). Detailed analysis is shown in Table 3.

Pleasure and relaxation were the most frequent reasons for deciding to use psychoactive compounds (Table 4). The most
Table 6. Answer distribution to the question "Considering recent 12 months, have you experienced any of these situations while being under the influence of psychoactive compounds?"

\begin{tabular}{|l|c|}
\hline Situation & $\mathbf{n}(\%)$ \\
\hline Driving a car & $3(0.6)$ \\
\hline Unwanted sexual experiences & $4(0.8)$ \\
\hline Problems with recalling any activities or places & $10(2.0)$ \\
\hline Theft & $2(0.4)$ \\
\hline Accident associated with physical injury & 0 \\
\hline Being involved in fight & $3(0.6)$ \\
\hline Being beaten & 0 \\
\hline Requiring immediate medical intervention & 0 \\
\hline Being a victim of sexual crime & $1(0.2)$ \\
\hline Break the law & $1(0.2)$ \\
\hline Being arrested & $1(0.2)$ \\
\hline Trying to commit suicide & $2(0.4)$ \\
\hline Passing exam & $7(1.4)$ \\
\hline Passing colloquium & $5(1.0)$ \\
\hline Participation in class/lecture & $6(1.2)$ \\
\hline
\end{tabular}

Table 7. Answer distribution to the question "Are psychoactive compounds present at the parties you usually attend?"

\begin{tabular}{|l|c|}
\hline Answer & $\mathbf{n}(\%)$ \\
\hline Always & $16(3.3)$ \\
\hline Very frequently & $13(2.7)$ \\
\hline Frequently & $53(10.8)$ \\
\hline Rarely & $118(24.1)$ \\
\hline Very rarely & $98(20.0)$ \\
\hline Never & $156(31.9)$ \\
\hline I never go to parties & $35(7.2)$ \\
\hline Total & $489(100.0)$ \\
\hline
\end{tabular}

frequently used psychoactive compounds, marijuana and hashish, were usually smoked (Table 5).

Most respondents neither declared undertaking risky behaviours while being under the influence of psychoactive compounds nor admitted experiencing negative consequences of their use. However, one should note that a fraction of these students also participated in academic classes while being under the influence of psychoactive compounds (Table 6).

Nearly $60 \%$ of respondents admitted that psychoactive compounds are available at the parties they attend (Table 7). An alarmingly high fraction of respondents declared that most of psychoactive compounds included in the study are easily available and can be obtained within one day notice (Tables 8 and 9). One should be alarmed by the fact that $19 \%$ respondents admitted being involved in the distribution of psychoactive compounds (Table 10). More than one fourth of respondents have been offered marijuana or hashish during the 12 months prior to the study (Table 11). 
Table 8. Answer distribution to the question "How difficult it would be for you to obtain these compounds?"

\begin{tabular}{|l|c|c|c|c|c|c|}
\hline Type of substance & Impossible & Very difficult & Quite difficult & Quite easy & Very easy & Do not know \\
\hline Marijuana or hashish & $50(9.9 \%)$ & $46(9.1 \%)$ & $48(9.5 \%)$ & $147(29.2 \%)$ & $92(18.3 \%)$ & $121(24.0 \%)$ \\
\hline Amphetamine (speed) & $69(13.7 \%)$ & $65(12.9 \%)$ & $73(14.5 \%)$ & $95(18.8 \%)$ & $27(5.4 \%)$ & $175(34.7 \%)$ \\
\hline Ecstasy & $73(14.5 \%)$ & $60(11.9 \%)$ & $67(13.3 \%)$ & $90(17.9 \%)$ & $28(5.6 \%)$ & $186(36.9 \%)$ \\
\hline LSD & $77(15.3 \%)$ & $64(12.7 \%)$ & $72(14.3 \%)$ & $70(13.9 \%)$ & $23(4.6 \%)$ & $198(39.3 \%)$ \\
\hline Psychoactive mushrooms & $88(17.5 \%)$ & $79(15.7 \%)$ & $73(14.5 \%)$ & $48(9.5 \%)$ & $19(3.8 \%)$ & $197(39.1 \%)$ \\
\hline Crack & $111(22.0 \%)$ & $87(17.3 \%)$ & $72(14.3 \%)$ & $38(7.5 \%)$ & $13(2.6 \%)$ & $183(36.3 \%)$ \\
\hline Heroin (including "brown sugar") & $115(22.8 \%)$ & $92(18.3 \%)$ & $72(14.3 \%)$ & $35(6.9 \%)$ & $11(2.2 \%)$ & $179(35.5 \%)$ \\
\hline So-called Polish heroin & $112(22.2 \%)$ & $87(17.3 \%)$ & $76(15.1 \%)$ & $35(6.9 \%)$ & $11(2.2 \%)$ & $183(36.3 \%)$ \\
\hline Cocaine & $115(22.8 \%)$ & $92(18.3 \%)$ & $66(13.1 \%)$ & $41(8.1 \%)$ & $13(2.6 \%)$ & $177(35.1 \%)$ \\
\hline Anabolic steroids & $102(20.2 \%)$ & $76(15.1 \%)$ & $62(12.3 \%)$ & $50(9.9 \%)$ & $37(7.3 \%)$ & $177(35.1 \%)$ \\
\hline Prescription hypnotics and psychotropic medications & $86(17.1 \%)$ & $57(11.3 \%)$ & $68(13.5 \%)$ & $64(12.7 \%)$ & $47(9.3 \%)$ & $182(36.1 \%)$ \\
\hline Other compounds & $70(13.9 \%)$ & $32(6.3 \%)$ & $29(5.8 \%)$ & $16(3.2 \%)$ & $14(2.8 \%)$ & $343(68.1 \%)$ \\
\hline
\end{tabular}

Table 9. Answer distribution to the question "How much time would you need to obtain these psychoactive compounds?"

\begin{tabular}{|l|c|c|c|c|c|c|c|}
\hline Type of substance & $\begin{array}{c}\text { Up to one } \\
\text { hour }\end{array}$ & Several hours & One day & Several days & Week or more & $\begin{array}{c}\text { I could not } \\
\text { reach }\end{array}$ & $\begin{array}{c}\text { Do not know } \\
\text { Marijuana or hashish }\end{array}$ \\
\hline $26(5.2 \%)$ & $51(10.1 \%)$ & $52(10.3 \%)$ & $106(21.0 \%)$ & $42(8.3 \%)$ & $38(7.5 \%)$ & $189(37.5 \%)$ \\
\hline Amphetamine (speed) & $12(2.4 \%)$ & $15(3.0 \%)$ & $39(7.7 \%)$ & $73(14.5 \%)$ & $46(9.1 \%)$ & $50(9.9 \%)$ & $269(53.4 \%)$ \\
\hline Ecstasy & $9(1.8 \%)$ & $14(2.8 \%)$ & $36(7.1 \%)$ & $67(13.3 \%)$ & $47(9.3 \%)$ & $52(10.3 \%)$ & $279(55.4 \%)$ \\
\hline LSD & $10(2.0 \%)$ & $12(2.4 \%)$ & $29(5.8 \%)$ & $54(10.7 \%)$ & $44(8.7 \%)$ & $62(12.3 \%)$ & $293(58.1 \%)$ \\
\hline Psychoactive mushrooms & $7(1.4 \%)$ & $12(2.4 \%)$ & $12(2.4 \%)$ & $53(10.5 \%)$ & $42(8.3 \%)$ & $78(15.5 \%)$ & $300(59.5 \%)$ \\
\hline Crack & $8(1.6 \%)$ & $5(1.0 \%)$ & $16(3.2 \%)$ & $46(9.1 \%)$ & $40(7.9 \%)$ & $98(19.4 \%)$ & $291(57.7 \%)$ \\
\hline Heroin (including "brown sugar") & $6(1.2 \%)$ & $7(1.4 \%)$ & $14(2.8 \%)$ & $45(8.9 \%)$ & $44(8.7 \%)$ & $97(19.2 \%)$ & $291(57.7 \%)$ \\
\hline So-called Polish heroin & $5(1.0 \%)$ & $7(1.4 \%)$ & $12(2.4 \%)$ & $48(9.5 \%)$ & $40(7.9 \%)$ & $98(19.4 \%)$ & $294(58.3 \%)$ \\
\hline Cocaine & $8(1.6 \%)$ & $7(1.4 \%)$ & $15(3.0 \%)$ & $51(10.1 \%)$ & $38(7.5 \%)$ & $94(18.7 \%)$ & $291(57.7 \%)$ \\
\hline Anabolic steroids & $11(2.2 \%)$ & $13(2.6 \%)$ & $22(4.4 \%)$ & $50(9.9 \%)$ & $33(6.5 \%)$ & $89(17.7 \%)$ & $286(56.7 \%)$ \\
\hline $\begin{array}{l}\text { Prescription hypnotics } \\
\text { and psychotropic medications }\end{array}$ & $19(3.8 \%)$ & $18(3.6 \%)$ & $25(5.0 \%)$ & $57(11.3 \%)$ & $29(5.8 \%)$ & $69(13.7 \%)$ & $287(56.9 \%)$ \\
\hline Other compounds & $6(1.2 \%)$ & $5(1.0 \%)$ & $9(1.8 \%)$ & $29(5.8 \%)$ & $14(2.8 \%)$ & $36(7.1 \%)$ & $405(80.4 \%)$ \\
\hline
\end{tabular}

Table 10. Answer distribution to the question "Considering recent 12 months, have you ever been involved in distribution of psychoactive compounds?"

\begin{tabular}{|c|c|c|c|}
\hline Situation & Yes & No & Do not remember \\
\hline Contacting somebody to have access to psychoactive compounds & $76(15.1 \%)$ & $403(80.0 \%)$ & $25(5.0 \%)$ \\
\hline Offering psychoactive compound to somebody & $15(3.0 \%)$ & $480(95.2 \%)$ & $9(1.8 \%)$ \\
\hline Selling psychoactive compound to somebody & $5(1.0 \%)$ & $490(97.2 \%)$ & $9(1.8 \%)$ \\
\hline
\end{tabular}

\section{DISCUSSION}

This study revealed that that the population of medical university students includes individuals who use psychoactive compounds at least occasionally. Comparing our results with the ones published in Polish and foreign literature suggests that the frequency of exposure of medical university students to psychoactive compounds represents a similar problem as that of their peers studying other disciplines $(10,11,13,16,22)$. The profile of psychoactive compounds used by our respondents was predominated by so-called soft drugs, i.e. marijuana and hashish. Also, this finding is consistent with literature evidence of the use of psychoactive substances among university students $(12,22)$.

Most of our respondents declared the age of the first contact with narcotics and the data suggest that this initiation usually occurred at the beginning of higher education. Also, literature data suggests that the beginning of education at a larger academic centre can promote many negative health behaviours including contact with psychoactive compounds (23). Many young individuals leave their family homes at that time and move to larger 
Table 11. Answer distribution to the question "Considering recent 12 months, have you ever been offered any of these compounds?"

\begin{tabular}{|l|c|}
\hline Type of substance & $\mathbf{n}(\%)$ \\
\hline Glues, solvents and other inhalation agents & $11(2.2)$ \\
\hline Marijuana or hashish & $134(26.6)$ \\
\hline Amphetamine (speed) & $41(8.1)$ \\
\hline Ecstasy & $30(6.0)$ \\
\hline LSD & $24(4.8)$ \\
\hline Psychoactive mushrooms & $17(3.4)$ \\
\hline Crack & $16(3.2)$ \\
\hline Heroin (including "brown sugar") & $16(3.2)$ \\
\hline So-called Polish heroin & $14(2.8)$ \\
\hline Cocaine & $19(3.8)$ \\
\hline Anabolic steroids & $16(3.2)$ \\
\hline Prescription hypnotics and psychotropic medications & $18(3.6)$ \\
\hline Other compounds & $5(1.0)$ \\
\hline
\end{tabular}

academic centres, where they live independently or in student houses. Under such circumstances, the lack of parental control promotes reaching for prohibited substances; this can be exacerbated by a negative stimulation from new friends and the higher availability of narcotics in larger agglomerations (24).

The problem of using psychoactive compounds by the students of medical universities can have serious health and social consequences. The results of many studies suggest that at least some individuals, after a period of experiments with so-called soft drugs, may also reach for stronger agents, which are associated with a serious risk of dependence development (25). Furthermore, negative consequences of risky behaviours undertaken under the influence of psychoactive compounds have been recently highlighted. These consequences include road accidents caused by young individuals driving under the influence of soft drugs (26). Furthermore, there is a risk of unwanted sexual contacts or even rape attempts on women dazed by psychoactive substances (4). The results of this study suggest that a certain group of our respondents had similar experiences as result of using substances of this type.

Besides these abovementioned social consequences of psychoactive compound use, the prevalence of this problem amongst medical university students is associated with additional specific threats. The principle risk pertains to the fact that the students of medical disciplines have easier access to clinical resources of psychoactive agents during their practical classes, as well as to prescriptions for narcotic compounds. This can promote their involvement in the distribution of this type of substances, and thus paving the road to criminal activity (27). This threat was confirmed by the results of our study; some of our respondents declared that they helped third parties to obtain psychoactive compounds at least once.

Alarmingly, the group of our respondents included individuals who declared participation in academic classes being under the influence of psychoactive compounds. Although such behaviour can be qualified as reprehensible in regards to individuals studying other disciplines, in case of medical university students such attitude can be associated with direct risk to health and life of patients with whom they are in contact during their practical and clinical classes.

Although not directly identified in our study, another threat pertains to non-recreational use of psychoactive compounds in order to facilitate learning (28). Literature data suggests that overloaded curricula of medical studies and high number of required exams can stimulate students to reach for this form of illegal support.

The limitation of this study is its questionnaire character. The results of previous attempts to determine the prevalence of such sensitive issues as substance dependence and alcoholism in various populations suggest that respondents frequently do not admit to have these kinds of problems (29). Consequently, one can assume that the extent of exposure to psychoactive compounds amongst medical university students, as revealed by our survey and other similar studies, is in fact underestimated. The fact that this study was directly supervised by the academic staff can constitute one potential reason for low declaration rates of using psychoactive compounds as a form of support during learning. However, in view of organizational and legal aspects, we do not have currently access to any other more precise tools enabling exact determination of the problem of substance dependence in larger populations.

Nevertheless, the results of this study point towards a necessity of intensified educational efforts directed at imprinting medical university students with the knowledge of harmful effects and risks associated with psychoactive compound use. Although most Polish medical universities have undertaken such activities in a framework of common programme that was initiated in 2004 (30), the results of our study suggest that one should constantly monitor their effectiveness and strive for its improvement. One principal role of the graduate of medical university pertains to health education of the community; this objective cannot be achieved if the educator himself does not represent the behaviours he is expected to promote.

In summary, the frequency of exposure of medical university students to psychoactive compounds represents a similar problem as that in their peers studying other disciplines. However, in view of its specific consequences (including potential threat to patients' health and life) the problem should not be underestimated.

\section{CONCLUSIONS}

The results of the survey show that majority of surveyed students do not consider taking soft drugs such as marijuana and hashish as a serious problem. Soft drugs are usually used during various events and are considered as a kind of part of student lifestyle. Current educational efforts implemented by the universities to raise awareness among students of the harmfulness of drugs are not sufficient. It is necessary to implement programmes promoting healthy ways of spending free time and other efforts to change student lifestyles.

\section{Conflict of Interests}

None declared

\section{REFERENCES}

1. European Monitoring Centre for Drugs and Drug Addiction. Annual report 2006: the state of the drugs problem in Europe. Lisbon: EMCDDA; 2006. 
2. Ptaszyńska-Sarosiek I, Wardaszka Z, Sackiewicz A, Okłota M, Niemcunowicz-Janica A. Cases of fatal para methoxy amphetamine (PMA) poisoning in the material of the Forensic Medicine Department, Medical University Of Białystok, Poland. Arch Med Sadowej Kryminol. 2009;59(3):190-3. (In Polish.)

3. Sutherland I, Shepherd JP. Social dimensions of adolescent substance use. Addiction. 2001;96(3):445-58.

4. Woynarowska B, Tabak I. Risk factors of early sexual initiation. Med Wieku Rozwoj. 2008;12(2 Pt 1):541-7. (In Polish.)

5. Niemcunowicz-Janica A, Wardaszka Z, Ptaszyńska-Sarosiek I. Determinations of the presence of drugs in traffic users in the material of the Department of Forensic Medicine, Medical University of Białystok. Arch Med Sadowej Kryminol. 2009;59(3):194-8. (In Polish.)

6. Siliquini R, Piat SC, Alonso F, Druart A, Kedzia M, Mollica A, et al. A European study on alcohol and drug use among young drivers: the TEND by Night study design and methodology. BMC Public Health. 2010;10:205. doi: 10.1186/1471-2458-10-205.

7. Hemphill SA, Heerde JA, Herrenkohl TI, Patton GC, Toumbourou JW, Catalano RF. Risk and protective factors for adolescent substance use in Washington State, the United States and Victoria, Australia: a longitudinal study. J Adolesc Health. 2011;49(3):312-20.

8. Łaszek M, Nowacka E, Szatko F. Negative behavior patterns of students. Part I. Consumption of alcohol and use of psychoactive substances. Probl Hig Epidemiol. 2011; 92(1):114-9. (In Polish.)

9. Rudzka, J, Krzyżanowski D. Knowledge of young people about addiction Piel Zdr Publ. 2011;1(3):225-34. (In Polish.)

10. Mellibruda J, Nikodemska S, Fronczyk K. Use and abuse of alcohol and other psychoactive substances among Polish university students. Med Wieku Rozwoj. 2003;7(1 Pt 2):135-55. (In Polish.)

11. Sałaga-Pylak M, Pikuła A, Kuśmierczyk K, Borzecki A. The occurrence of addictions among high school students. Ann Univ Mariae Curie Sklodowska Med. 2004;59(1):402-5.

12. Morawska J, Krawczyk E, Satora L. Assessment of legal awareness regarding illicit drug use among Kraków university students. Przegl Lek. 2005;62(6):354-6. (In Polish.)

13. Motyka A, Leszkiewicz M, Majchrzak A, Majewski M, Adamek R. Consumption of psychoactive substances - awareness of health consequences among the students of university schools in Poznan. Przegl Lek. 2007;64(10):808-10. (In Polish.)

14. Ogonowska D, Pach D, Targosz D. The usage of psychoactive substances among secondary school students in Nowy Sacz. Przegl Lek. 2009;66(6):293-300. (In Polish.)

15. Modrzejewska R. Comorbidity in adolescence: simultaneous declaration of depressive, eating, obsessive-compulsive symptoms and use of psychoactive substances in the general population of 17 year old students in a big city. Psychiatr Pol. 2010;44(5):651-63. (In Polish.)

16. Kuczyński J, Kleszczewska E, Popławski T, Łogwiniuk K, Szpakow A Szpakow A. The study of psychoactive substance use and health-related attitudes among students from Suwalki, Bialystok and Grodno. Probl Hig Epidemiol. 2011;92(4):748-53. (In Polish.)

17. Bunch WH, Storr CL, Hughes PH, Baldwin DC Jr. Substance use by surgical residents and students entering surgery. J Surg Res. 1996;61(1):108-12.

18. Wójtowicz-Chomicz K, Kowal M, Wójtowicz M, Borzęcki A. Evaluation of anti-healthy behavior among students of Medical University in Lublin. Probl Hig Epidemiol. 2007; 88(1):108-11. (In Polish.)

19. Szczyrba-Maroń B. Strategies to cope with stress taking into consideration usage of psychoactive substances among group of nursing students. Probl Pielęgn. 2010;18(4):455-60. (In Polish.)

20. Marcinkowski JT. Epidemiology of substance abuse in Poland - with focus on medical professions. Hygeia Publ Health. 2011;46(3):334-8. (In Polish.)

21. Klimberg A, Marcinkowski JT, Przybylski J. Consumption of alcohol and other psycho-active substances among the students of selected medical university faculties. Part IV. Alcohol consumption-related behaviours. Probl Hig Epidemiol. 2009;90(2): 218-21. (In Polish.)

22. Kułak A, Shpakov A, Kułak P. Preliminary analysis of the problem of nicotine, alcohol and drug addictions in the student population. Probl Hig Epidemiol. 2011;92(1):137-45. (In Polish.)

23. Bargiel-Matusiewicz K, Grzelak S, Weglinska M. Factors protecting against risk behavior concerning the psychoactive substances used by adolescents. Int J Adolesc Med Health. 2010;22(4):503-10.

24. Dielman TE, Butchart AT, Shope JT, Miller M. Environmental correlates of adolescent substance use and misuse: implications for prevention programs. Int J Addict. 1990-1991;25(7A-8A):855-80.

25. Vázquez FL. Psychoactive substance use and dependence among Spanish university students: prevalence, correlates, polyconsumption, and comorbidity with depression. Psychol Rep. 2010;106(1):297-313.

26. Asbridge M, Poulin C, Donato A. Motor vehicle collision risk and driving under the influence of cannabis: evidence from adolescents in Atlantic Canada. Accid Anal Prev. 2005;37(6):1025-34.

27. Rozenbroek K, Rothstein WG. Medical and nonmedical users of prescription drugs among college students. J Am Coll Health. 2011;59(5):358-63.

28. Watkins C. Use of amphetamine by medical students. South Med J. 1970 Aug;63(8):923-9.

29. Machado Neto Ade S, Andrade TM, Fernandes GB, Zacharias HP, Carvalho FM, Machado AP, et al. Reliability of a questionnaire on substance use among adolescent students. Brazil. Rev Saude Publica. 2010;44(5):830-9.

30. Pach J, Tobiasz-Adamczyk B, Jabłoński P, Brzyski P, Krawczyk E, Satora $\mathrm{L}$, et al. Drug free universities - trends in illicit drugs use among Kraków university students. Przegl Lek. 2005;62(6):342-50. (In Polish.)

Received November 14, 2015 Accepted in revised form December 7, 2016 